\title{
Growth and Structural Characterizations of Nanostructured Chromium-Zirconium-Nitride Thin Films for Tribological Applications
}

\author{
Pattira Homhuan ${ }^{1, * 1}$, Surasing Chaiyakun ${ }^{2}$, Rattaporn Thonggoom ${ }^{3,4}$, \\ Nurot Panich ${ }^{5}$ and Sukkaneste Tungasmita ${ }^{5,6, * 2}$ \\ ${ }^{1}$ Nanoscience and Technology, Graduate School, Chulalongkorn University, Bangkok, 10330, Thailand \\ ${ }^{2}$ Department of Physics, Faculty of Science, Burapa University, Chonburi, 20131, Thailand \\ ${ }^{3}$ Department of Chemistry, Faculty of Science, Mahidol University, Bangkok, 10400, Thailand \\ ${ }^{4}$ Center for Surface Science and Engineering, Faculty of Science, Mahidol University, Bangkok, 10400, Thailand \\ ${ }^{5}$ Center of Innovative Nanotechnology, Chulalongkorn University, Bangkok, 10330, Thailand \\ ${ }^{6}$ Department of Physics, Faculty of Science, Chulalongkorn University, Bangkok, 10330, Thailand
}

\begin{abstract}
Nanostructured $\mathrm{Cr}-\mathrm{Zr}-\mathrm{N}$ thin films were grown on $\mathrm{Si}(100)$ substrates in a mixture of $\mathrm{Ar}$ and $\mathrm{N}_{2}$ plasma. The nitrogen partial pressure was varied to produce and control the stoichiometric forms obtained. All the $\mathrm{Cr}-\mathrm{Zr}-\mathrm{N}$ films exhibited a nanostructure with an average grain size of less than $10 \mathrm{~nm}$, as determined by X-ray diffractogram analysis, and were formed in the solid-solution. As the contents of nitrogen in the film increased, it lead to changes in the crystal texture and competitive growth. The maximum root mean square roughness was $7.87 \mathrm{~nm}$ at a $20 \%$ nitrogen partial pressure and the roughness tended to decrease as the grain size decreased. The nano-indentation showed that the films grown at a $20 \%$ nitrogen partial pressure and annealed at $700^{\circ} \mathrm{C}$ had the highest reduced modulus and hardness at 349.2 and $35.1 \mathrm{GPa}$, respectively. The mechanical properties of films can be improved by a post-annealing heat treatment. With respect to the electrical properties of these films, the sheet resistance, which is related to the defect level, tended to increase as the nitrogen partial pressure increased. [doi:10.2320/matertrans.M2010140]
\end{abstract}

(Received April 20, 2010; Accepted June 10, 2010; Published July 28, 2010)

Keywords: magnetron sputtering, nanostructure, hard coating, protective thin films

\section{Introduction}

Transition-metal-nitride thin films deposited by physical vapor deposition (PVD) have been developed and used as mechanically and chemically protective layers for industrial applications for many years. The cubic-base structural chromium nitride $(\mathrm{CrN})$ is a more recent and interesting choice of such layers due to its well-matched properties to some industrial requirements, especially those that require a hard coating and for tribological applications. This is largely due to the fact that $\mathrm{CrN}$ films have a high hardness, high wear- and corrosion-resistance, and also have a low frictioncoefficient. $^{1,2)}$ Adding one more metal element to form Cr-based ternary nitride films has been reported to show improved properties compared to the binary $\mathrm{CrN}$ compound. ${ }^{3-5)}$ However, in the case of $\mathrm{Zn}$, as an example added tertiary metal element, there is an apparent lack of important information about the properties of the ternary $\mathrm{Cr}-\mathrm{Zr}-\mathrm{N}$ films derived from various growth parameters, despite the fact that these are the key variables for engineering the desired properties of the material. In this work, we explored the role of the nitrogen partial pressure during film formation, and that of the post-process annealing temperature, on the structural, mechanical and electrical properties of the resultant $\mathrm{Cr}-\mathrm{Zr}-\mathrm{N}$ film.

\section{Experimental Procedures}

Ternary Cr-Zr-N films were grown by dual unbalanced D.C. magnetron sputtering with horizontal magnetron

\footnotetext{
${ }^{* 1}$ Graduate Student, Chulalongkorn University

*2 Corresponding author, E-mail: Sukkaneste.t@chula.ac.th
}

sources on $\mathrm{Si}(100)$ substrates. All films were produced from pure $\mathrm{Cr}$ and $\mathrm{Zr}$ targets in a defined mixture of $\mathrm{Ar}$ and $\mathrm{N}_{2}$ plasma. The base pressure in this reactive sputtering system was pumped down to $5 \times 10^{-5}$ mbar. The partial pressure of nitrogen $\left(\mathrm{N}_{2} / \mathrm{Ar}+\mathrm{N}_{2}\right)$ during the process was varied to produce various compositions of films. During the formation of films, the discharge current of each target was controlled at a constant $0.5 \mathrm{~A}$. All films were grown without an extra heat source, except the transferred energy at the substrate surface from the collision of adatoms and plasma species. In this work, the substrate was at a floating potential. The thickness of all the films obtained was in the range of $0.9-2.0 \mu \mathrm{m}$, depending on the nitrogen partial pressure used during their growth.

The elemental composition of each film was measured by energy dispersive spectroscopy (EDS) (Oxford INCA), coupled to a scanning electron microscope (JEOL JSM$6480 \mathrm{LV}$ ), that was also used for scanning electron microcopy (SEM). For the structural characterization of films, the specimens were characterized by X-ray diffraction (XRD) (Brukers D8 Discover) with $\mathrm{Cu} \mathrm{K} \alpha(\lambda=0.15406 \mathrm{~nm})$ as the X-ray source. The cross-sectional microstructure was investigated by transmission electron microscopy (TEM) (JEOL JEM-2010 $200 \mathrm{kV}$ transmission electron microscope). The surface topography was investigated by atomic force microscopy (AFM) (Veeco Nanoscope-IV).

The hardness and reduced modulus were both measured using a Micro Material Nano Test in the constant depth mode with a Berkovich pyramidal indenter tip. To avoid the effect of substrate, the depth of indentation was limited to less than $1 / 10$ that of the film thickness, which in this case meant the depth was taken at about $100 \mathrm{~nm}$. The sheet-resistance of the film material was evaluated by the van der Pauw method. The 


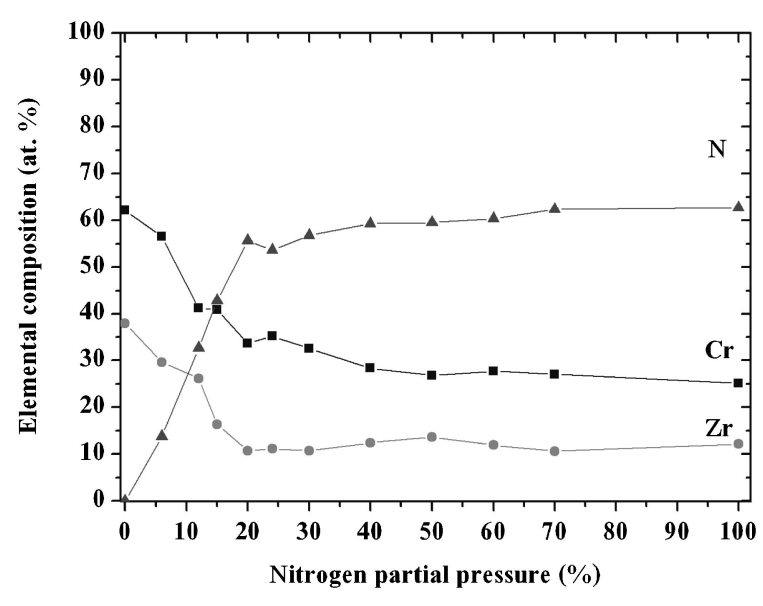

Fig. 1 Elemental concentrations of $\mathrm{Cr}-\mathrm{Zr}-\mathrm{N}$ films formed with different nitrogen partial pressures. Elemental concentrations are shown for $\mathrm{N}$ (triangles), $\mathrm{Cr}$ (squares) and $\mathrm{Zr}$ (circles).

stoichiometric $\mathrm{Cr}-\mathrm{Zr}-\mathrm{N}$ films grown at a $20 \%$ nitrogen partial pressure were used for the study of the effect of the postgrowth annealing temperature under an Ar flow at vacuum pressure for $1 \mathrm{~h}$, and then cooled down. The ramping rate of the annealing reaction was $5^{\circ} \mathrm{C} / \mathrm{min}$.

\section{Results and Discussion}

\subsection{Effect of nitrogen partial pressure}

\subsubsection{Chemical composition}

The elemental concentrations of $\mathrm{Cr}, \mathrm{Zr}$ and $\mathrm{N}$ in the asdeposited films on silicon (100) substrates derived under different nitrogen partial pressures are shown in Fig. 1. The nitrogen composition in the films increased essentially linearly with increasing nitrogen partial pressure up to a nitrogen partial pressure of $20 \%$, and thereafter remained almost constant and largely numerically and statistically independent of the nitrogen partial pressure. This represents the saturated condition for nitrogen atoms incorporation into the film material. Moreover, at all nitrogen partial pressures, there was a higher concentration of $\mathrm{Cr}$ than $\mathrm{Zr}$, because $\mathrm{Cr}$ has a higher sputtering yield compared to that for $\mathrm{Zr}{ }^{6}{ }^{6}$ By increasing the nitrogen partial pressure, the reaction rate between nitrogen and metal at the target surface increases, which causes the sputtered nitrogen atoms and some of the metal-nitrogen cluster particles from the surface target to also increase. ${ }^{7)}$ In contrast, the relative proportion of sputtered $\mathrm{Zr}$ and $\mathrm{Cr}$ atoms from the surface target that form films decreases due to the increased coverage of nitrogen on the surface, resulting in the formation of metal nitride on the surface of the metallic target. The sputter yield for the nitride material at the target surface is much lower than that for the metal, which causes the deposition rate of films to decrease as the percentage of nitrogen partial pressure increases (see Fig. 2).

\subsubsection{Structural properties}

Figure 3 shows representative X-ray diffraction (XRD) spectra of the Cr-Zr-N films grown under the different nitrogen partial pressures, plotted on a semi-log scale. Since the $\mathrm{Cr}-\mathrm{Zr}-\mathrm{N}$ ternary compound came from the combination of $\mathrm{CrN}$ and $\mathrm{ZrN}$ materials, which alone both have a rock-salt

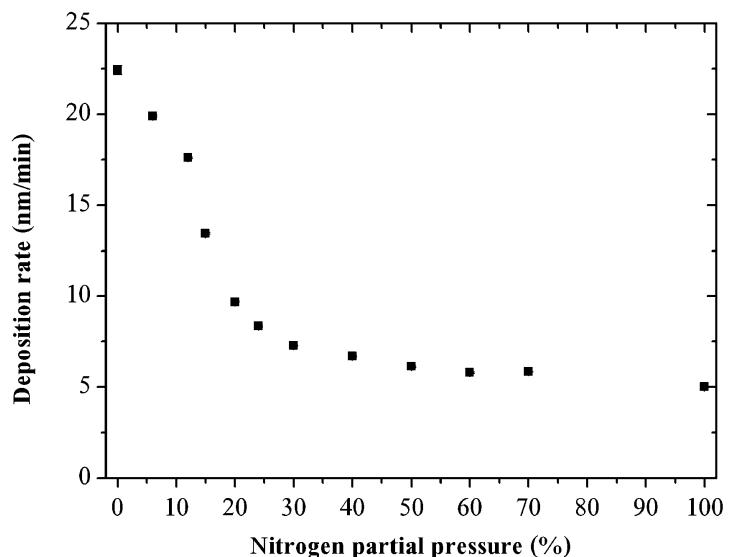

Fig. 2 Deposition rate of $\mathrm{Cr}-\mathrm{Zr}-\mathrm{N}$ films as a function of the nitrogen partial pressure.

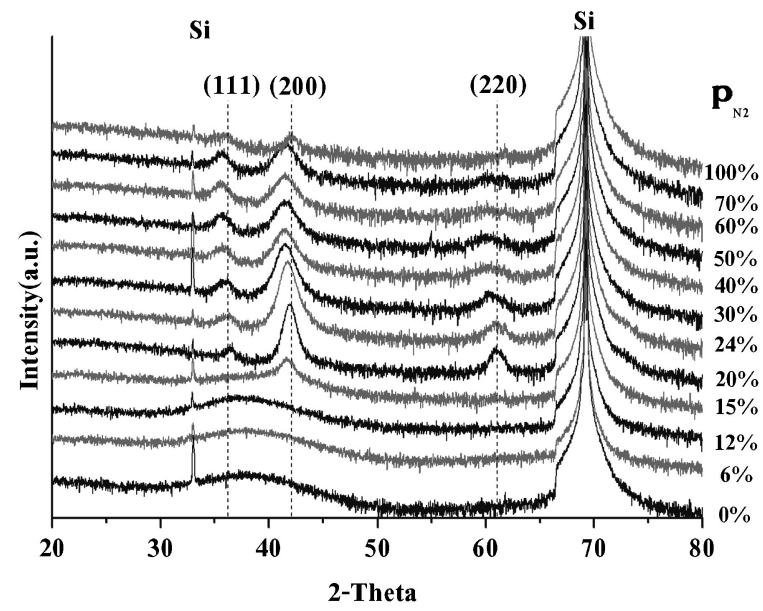

Fig. 3 Representative XRD spectra of $\mathrm{Cr}-\mathrm{Zr}-\mathrm{N}$ films grown at the indicated different nitrogen partial pressures.

$\mathrm{NaCl}$ type crystal structure, then the $\mathrm{Cr}-\mathrm{Zr}-\mathrm{N}$ also seems to retain a $\mathrm{NaCl}$-like crystal structure. The peak positions for some major orientations of the $\mathrm{Cr}-\mathrm{Zr}-\mathrm{N}$ materials as a function of the $\mathrm{Zr} / \mathrm{Cr}$ ratio have been calculated and presented elsewhere. ${ }^{4)}$ Here, according to EDS results, the composition of the material becomes stable after a $20 \%$ nitrogen partial pressure was applied and exhibits a pattern similar to the $\mathrm{Cr}_{0.7} \mathrm{Zr}_{0.3} \mathrm{~N}$ form in the ICDD 03-065-9004 database, with a NaCl-like structure. The $\mathrm{Cr}_{0.7} \mathrm{Zr}_{0.3} \mathrm{~N}(200)$ form starts to develop from a nitrogen partial pressure of $15 \%$, whilst the (200) plane is the preferable orientation when formed over and above a $15 \%$ nitrogen partial pressure because of the dominant surface energy. The $\mathrm{Cr}_{0.7} \mathrm{Zr}_{0.3} \mathrm{~N}(200)$ is more stable and has the lowest surface energy. ${ }^{8)}$ However, the lowest strain energy is found with $\mathrm{Cr}_{0.7} \mathrm{Zr}_{0.3} \mathrm{~N}(111)$ and is the preferred orientation for $\mathrm{CrN}$ at low temperature growth. $\left.{ }^{9}\right)$ Accordingly, the development of texture in the $\mathrm{Cr}-\mathrm{Zr}-\mathrm{N}$ films can be changed from that of $\mathrm{CrN}$ alone by control of the ternary metal and nitrogen partial pressure. This can be explained by re-nucleation, due to the addition of zirconium in the films. ${ }^{10)}$ Whilst the formation (detection) of both the $\mathrm{Cr}_{0.7} \mathrm{Zr}_{0.3} \mathrm{~N}(111)$ and the $\mathrm{Cr}_{0.7} \mathrm{Zr}_{0.3} \mathrm{~N}(220)$ forms started to appear at a $20 \%$ nitrogen partial pressure, as the nitrogen partial pressure increases 
$2 \mu \mathrm{m}$

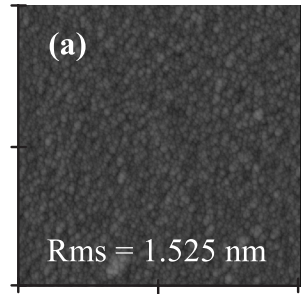

0
$2 \mu \mathrm{m}$

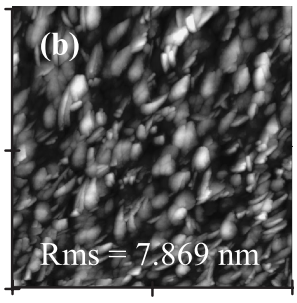

20
$2 \mu \mathrm{m}$

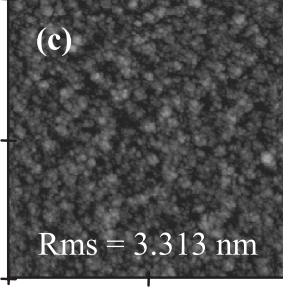

$\mu \mathrm{m}$
$2 \mu \mathrm{m}$

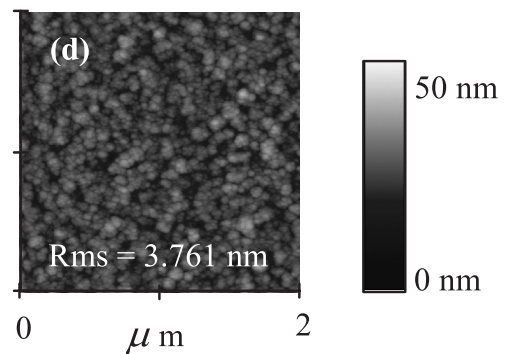

Fig. 4 Representative AFM images of Cr-Zr-N films formed under different nitrogen partial pressures of (a) 6\%, (b) 20\%, (c) 50\% and (d) $100 \%$

further above $20 \%$ the position of these peaks shifts slightly towards the lower diffraction angles. This may be related to an increase in the compressive stress in the film due to the formation of a solid solution. ${ }^{10)}$ In addition, changes in the atomic density of the crystalline films can be considered. The density values of (200), (220) and (111) represent 4, 2.83 and $2.31 \mathrm{at} / \mathrm{a}^{2}$, respectively. As the nitrogen partial pressure increases, so the adatoms are arranged to form films in lower density planes because the mobility of the adatoms is limited, and the energy of sputtered atoms decreases with increasing in the nitrogen partial pressures. ${ }^{11)}$

The size of the formed grains was evaluated from the XRD peaks using the Scherer formula. All films have a grain size of less than $10 \mathrm{~nm}$, but are perhaps even smaller since this value ignores the fact that the peak can be broad from the residual stress. ${ }^{12)}$ Therefore, the result indicates that all the films were conform to a Zone 1 model in the Thornton's structure zone model, with a low substrate temperature. In this zone, adatoms have a low surface diffusion because of a low substrate temperature and, since the adatoms are insufficient to overcome the shadowing effect, the films have a typical small-width columnar structure with voids with a rough surface. ${ }^{13,14)}$

\subsubsection{Cross-sectional and surface morphology}

The surface morphology of the Cr-Zr-N films, as evaluated by AFM, as a function of the nitrogen partial pressure is shown in Fig. 4. The maximum root mean square roughness was $7.87 \mathrm{~nm}$ at a $20 \%$ nitrogen partial pressure, because of the competition among the Cr-Zr-N(111), (200) and (220), whilst the roughness tended to decrease as the grain size decreased. ${ }^{15)}$ A typical TEM micrograph of a $\mathrm{Cr}-\mathrm{Zr}-\mathrm{N}$ film grown at a $20 \%$ nitrogen partial pressure is shown in Fig. 5, along with an electron diffraction pattern. The microstructure of the film has a clear dense columnar structure, with some voids visible in the film material, whilst the average domain size is about or less than $10 \mathrm{~nm}$. This particle domain size conforms well to that calculated from the XRD data.

\subsubsection{Mechanical properties}

With respect to the mechanical properties of hard coatings, the hardness and reduced modulus are the two most important properties of films and so were evaluated. Both the hardness and the reduced modulus of the $\mathrm{Cr}-\mathrm{Zr}-\mathrm{N}$ films, plotted as a function of the nitrogen partial pressure, were maximal when formed under a $20 \%$ nitrogen partial pressure (Fig. 6). At their maximum hardness and reduced modulus (30.0 and $324.1 \mathrm{GPa}$, respectively), they were nearly stoichiometric

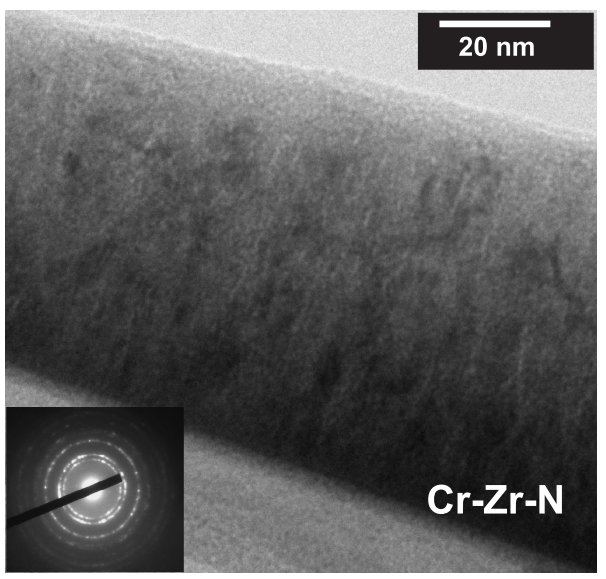

Fig. 5 Representative cross-sectional micrograph of a Cr-Zr-N film formed at a $20 \%$ nitrogen partial pressure, with an electron diffraction pattern shown in the insert.

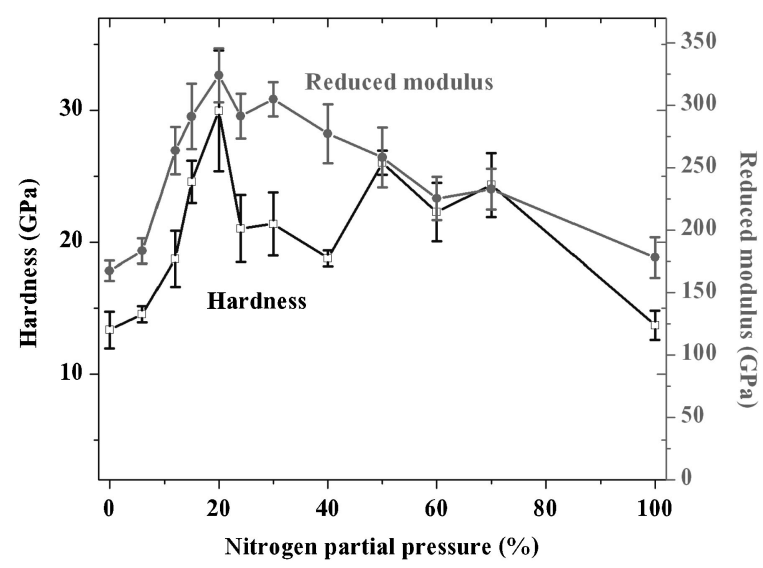

Fig. 6 Hardness and reduced modulus of $\mathrm{Cr}-\mathrm{Zr}-\mathrm{N}$ films as a function of the nitrogen partial pressure.

with a $\mathrm{Zr}_{0.3} \mathrm{Cr}_{0.7} \mathrm{~N}$ form that was in good agreement with that for ICDD 03-065-9004 in the database. From these results the roughness and grain diameter appear to be related to the hardness, as there is competition among (111), (200) and (220) planes. Moreover, the hardness strongly depends on the nitrogen contents in the films, as shown by the dosedependence to the nitrogen partial pressure over from 0 to $20 \%$ range. This maximum hardness of the $\mathrm{Cr}-\mathrm{Zr}-\mathrm{N}$ film, when grown at a $20 \%$ nitrogen partial pressure, consists of 


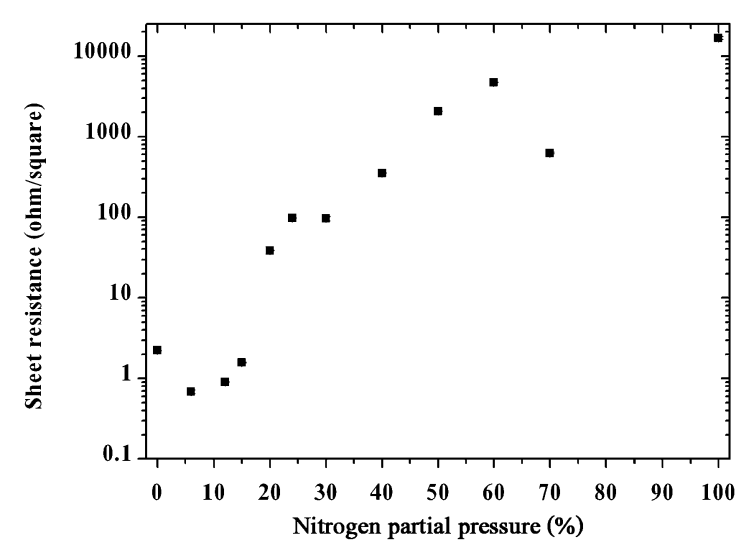

Fig. 7 The sheet resistance of $\mathrm{Cr}-\mathrm{Zr}-\mathrm{N}$ films developed with different nitrogen partial pressures.

the maximum amount of nitrogen completely bonded with metallic atoms. ${ }^{16)}$ However, that it then declines with further increases in nitrogen partial pressures, rather than remains at same saturation level, is due to the fact that higher partial pressures of nitrogen lead to a larger excess of nitrogen in the films located in the interstitial sites. This form of solid solution has a high hardness because the $\mathrm{Zr}$ atoms, which substitute for the $\mathrm{Cr}$ atoms in the face-center-cubic-structure, are limited to the mobility of dislocation.

The strength of adhesion between each of the different $\mathrm{Cr}$ $\mathrm{Zr}-\mathrm{N}$ films and the silicon (100) substrate was tested by nanoscratch, where the critical load is determined by a sudden change in the penetration depth in scratch tests. By this method, a maximum critical load $\left(L_{\mathrm{C}}\right)$ of $2.1 \mathrm{~N}$ was obtained with films produced at a $15 \%$ nitrogen partial pressure, and decreased thereafter at higher nitrogen partial pressures (data not shown). Thus, $\mathrm{Cr}-\mathrm{Zr}-\mathrm{N}$ films grown at a $15 \%$ nitrogen partial pressure had the best adhesion to the silicon (100) substrate. That the adhesion of films tended to decrease as the nitrogen partial pressure was increased is because the adatoms under these conditions have less energy to form films.

\subsubsection{The electrical properties}

The observed relationship between the $\mathrm{Cr}-\mathrm{Zr}-\mathrm{N}$ sheet resistance and the nitrogen partial pressure was almost linear with the sheet resistance increasing markedly as the nitrogen partial pressure increases (Fig. 7). The change in the sheet resistance is inversely proportional to the mean free path of conduction electrons, which relates to the microstructure and defect of the films. ${ }^{17)}$ Therefore, a lower sheet resistance is likely to mean that there are fewer defects in the film. Initially, $\mathrm{Cr}-\mathrm{Zr}-\mathrm{N}$ films, grown at a low nitrogen partial pressure, have a lower sheet resistance than $\mathrm{Cr}-\mathrm{Zr}$ films because the nitrogen atoms incorporate into the films and bond with the $\mathrm{Cr}$ and $\mathrm{Zr}$ atoms. After saturation a higher nitrogen content in the films then makes for more impurity point defects, which can be found in the solid solution, because the excess of either nitrogen or metal atoms can situate on the interstitial site or grain-boundary. ${ }^{18,19)}$ When the partial pressure of nitrogen increases, there are many grain-boundaries in the film because the adatoms do not have enough energy to re-nucleate the crystallographic orientation. With more nitrogen incorporate in the film structure, the
Table 1 The properties of the $\mathrm{Cr}-\mathrm{Zr}-\mathrm{N}$ films grown at a $20 \%$ nitrogen partial pressure and subsequentially treated at different annealing temperatures.

\begin{tabular}{ccccc}
\hline $\begin{array}{c}\text { Annealing } \\
\text { Temp } \\
\left({ }^{\circ} \mathrm{C}\right)\end{array}$ & Composition & $\begin{array}{c}\text { Hardness } \\
(\mathrm{GPa})(\mathrm{H})\end{array}$ & $\begin{array}{c}\text { Reduced } \\
\text { modulus } \\
(\mathrm{GPa})(\mathrm{E})\end{array}$ & $\mathrm{H} / \mathrm{E}^{*}$ \\
\hline 0 & $\mathrm{Cr}_{0.33} \mathrm{Zr}_{0.11} \mathrm{~N}_{0.56}$ & $30.0 \pm 4.6$ & $324.1 \pm 21.7$ & 0.092 \\
300 & $\mathrm{Cr}_{0.31} \mathrm{Zr}_{0.11} \mathrm{~N}_{0.58}$ & $30.0 \pm 3.8$ & $320.3 \pm 14.0$ & 0.094 \\
500 & $\mathrm{Cr}_{0.35} \mathrm{Zr}_{0.12} \mathrm{~N}_{0.53}$ & $33.3 \pm 3.2$ & $323.7 \pm 23.8$ & 0.102 \\
700 & $\mathrm{Cr}_{0.32} \mathrm{Zr}_{0.11} \mathrm{~N}_{0.57}$ & $35.1 \pm 4.7$ & $349.2 \pm 18.6$ & 0.101 \\
\hline$* \mathrm{H} / \mathrm{E}=$ The ratio between hardness $(\mathrm{GPa})$ and reduced modulus $(\mathrm{GPa})$
\end{tabular}

${ }^{*} \mathrm{H} / \mathrm{E}=$ The ratio between hardness $(\mathrm{GPa})$ and reduced modulus $(\mathrm{GPa})$

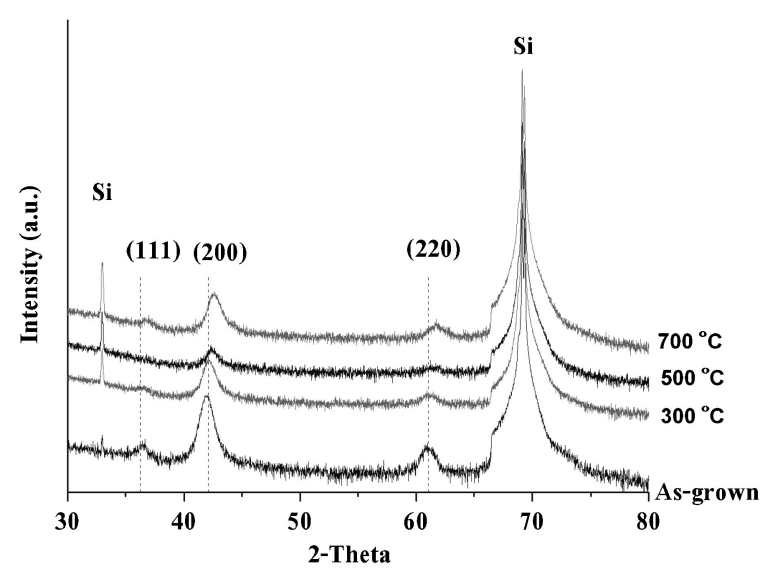

Fig. 8 Representative XRD spectra of $\mathrm{Cr}-\mathrm{Zr}-\mathrm{N}$ films grown at different annealing temperatures.

material shows a ceramic-like property. Therefore, overstoichiometric films exhibit the highest sheet resistance than the other films.

\subsection{Effect of annealing temperature}

$\mathrm{Cr}-\mathrm{Zr}-\mathrm{N}$ films grown at a $20 \%$ nitrogen partial pressure were then annealed at 300,500 or $700^{\circ} \mathrm{C}$ to investigate the thermal stability of the films formed. With respect to the elemental composition, these did not significantly change after annealing (Table 1).

Figure 8 shows the typical XRD spectra of $\mathrm{Cr}-\mathrm{Zr}-\mathrm{N}$ films grown at a $20 \%$ nitrogen partial pressure with different postannealing temperature treatment, plotted on a semi-log scale. The (200) plane remains the preferred orientation in all samples, and the diffraction peaks shift towards the higher diffraction angles as the annealing temperature increases, indicating that the lattice constant decreases as the annealing temperature increases. This is presumably because nitrogen atoms can diffuse from the grain boundary or the interstitial site to empty lattice sites. ${ }^{20)}$ Still, there is no phase separation after annealing at $700^{\circ} \mathrm{C}$, indicating the thermodynamic stability of these films.

The hardness tends to increase as the annealing temperature increases, reaching a maximum reduced modulus and hardness of 349.2 and $35.1 \mathrm{GPa}$, respectively, after annealing at $700^{\circ} \mathrm{C}$ for $1 \mathrm{~h}$ (Table 1$)$. The post-annealing treatment makes the modification of grain boundary of the film structure. Since the films were grown at low temperatures, all of them exhibited typical fine columnar structure. The 
$2 \mu \mathrm{m}$

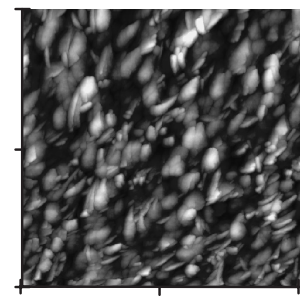

0
$2 \mu \mathrm{m}$

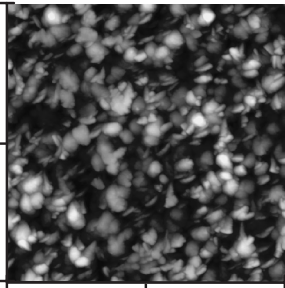

20
$2 \mu \mathrm{m}$

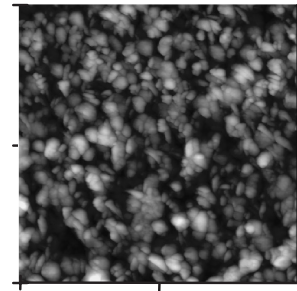

$\mu \mathrm{m}$
$2 \mu \mathrm{m}$

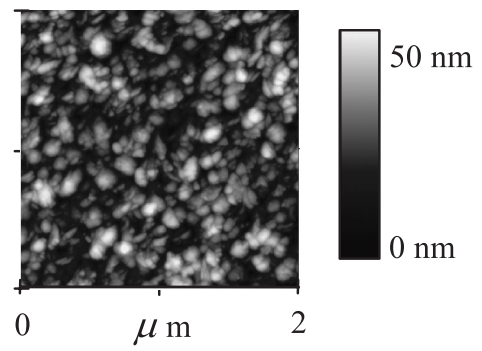

Fig. 9 Representative AFM images of Cr-Zr-N films; (a) as-deposited specimen, and specimens annealed at (b) $300^{\circ} \mathrm{C}$, (c) $500^{\circ} \mathrm{C}$ and (d) $700^{\circ} \mathrm{C}$.

post-annealing process can cause lattice vibration and introduces grain boundary annihilation mechanism. This results in an increasing of domain width and the changing in crystal structure.

The wear resistance of the films can be found from the ratio between the hardness and modulus, ${ }^{21)}$ and revealed that $\mathrm{Cr}-\mathrm{Zr}-\mathrm{N}$ films grown at a $20 \%$ nitrogen partial pressure and annealed at $500^{\circ} \mathrm{C}$ had the maximum value (highest wear resistance). After annealing, the RMS roughness was not changed (Fig. 9).

\section{Conclusions}

Chromium zirconium nitride films were grown at different nitrogen partial pressures $(0-100 \%)$ on silicon (100) substrates. The nitrogen partial pressure was observed to play an important role in the stoichiometry, microstructure, deposition rate, surface morphology, sheet-resistance and hardness of the obtained $\mathrm{Cr}-\mathrm{Zr}-\mathrm{N}$ films due to the incorporation of nitrogen into the films. This phenomenon leads to the creation, and competitive growth, of the texture and surface roughness of the films. The films developed from a random oriented crystalline structure to a texture-crystalline structure at nitrogen partial pressures of $15 \%$. The solid solution material was formed without any evidence of phase separation between the $\mathrm{CrN}$ and the $\mathrm{ZrN}$. The hardness of the film did not seem to significantly depend on the content of nitrogen, but rather was related to the equilibrium site. The $\mathrm{Cr}_{0.32} \mathrm{Zr}_{0.11} \mathrm{~N}_{0.57}$ film, grown at a $20 \%$ nitrogen partial pressure and annealed at $700^{\circ} \mathrm{C}$, had the highest hardness and reduced modulus. The sheet resistance of $\mathrm{Cr}-\mathrm{Zr}-\mathrm{N}$ films tended to increase with increasing nitrogen partial pressure. The films had thermal stability up to $700^{\circ} \mathrm{C}$.

\section{Acknowledgements}

The authors would like to thank Mr. Nuttapong Parncharoenthaworn for helping measure the nanoindentation and The Commission on Higher Education and Graduate
Thesis Grant for financial support that enabled this research work to be performed.

\section{REFERENCES}

1) J. Lin, Z. L. Wu, X. H. Zhang, B. Mishra, J. J. Moore and W. D. Sproul: Thin Solid Films 517 (2009) 1887-1894.

2) S. H. Shin, M. W. Kim, M. C. Kang, K. H. Kim, D. H. Kwon and J. S. Kim: Surf. Coat. Technol. 202 (2008) 5613-5616.

3) S. M. Aouadi, T. Maeruf, R. D. Twesten, D. M. Mihut and S. L. Rohde: Surf. Coat. Technol. 200 (2006) 3411-3417.

4) G. S. Kim, B. S. Kim, S. Y. Lee and J. H. Hahns: Surf. Coat. Technol. 200 (2005) 1669-1675.

5) R. Lamni, R. Sanjines, M. Parlinska-Wojtan, A. Karimi and F. Levy: J. Vac. Sci. Technol. A 23 (2005) 593-598.

6) G. E. McGuire (Ed): Semiconductor Materials and Process Technology Handbook for Very Large Scale Integration (VLSI) and Ultra Large Scale Integration (ULSI), (Noyes Publications, New Jersey, 1988) p. 373.

7) S. Hofmann: Thin Solid Films 191 (1990) 335-348.

8) J. L. Ruan, J. L. Huang, J. S. Chen and D. F. Lii: Surf. Coat. Technol. 200 (2005) 652-1658.

9) P. Homhoul, C. Thavornthira, S. Chaiyakun and S. Tungasmita: J. Sci. Res. Chula Uni. 33 (2008) 43-49.

10) G. Ababias: Surf. Coat. Technol. 202 (2008) 2223-2235.

11) L. Combadiere and J. Machet: Surf. Coat. Technol. 88 (1996) 17-27.

12) S. Ulrich, H. Holleck, J. Ye, H. Leiste, R. Loos, M. Stuber, P. Pesch and S. Sattel: Thin Solid Films 437 (2003) 164-169.

13) S. PalDey and S. C. Deevi: Mater. Sci. Eng. A 342 (2003) 58-79.

14) G. E. McGuire (Ed): Semiconductor Materials and Process Technology Handbook for Very Large Scale Integration (VLSI) and Ultra Large Scale Integration (ULSI), (Noyes Publications, New Jersey, 1988) p. 415.

15) Z. X. Song, Y. Wang, C. J. F. Wang, C. L. Liu and K. W. Xu: Surf. Coat. Technol. 202 (2007) 5412-5415.

16) R. D. Arnell, J. S. Colligon, K. F. Minnebaev and V. E. Yurasova: Vacuum 47 (1996) 425-431.

17) Y. K. Lee, J. Y. Kim, Y. K. Lee, M. S. Lee, D. K. Kim, D. Y. Jin, T. H. Nam, H. J. Ahn and D. K. Park: J. Crystal Growth 234 (2002) 498-504.

18) L. Hulman, U. Helmersson, S. A. Barnett, J.-E. Sundgren and J. E. Greene: J. Appl. Phys. 61 (1987) 552-555.

19) D. William and Jr. Callister: Material Science and Engineering an Introduction 6 ed., (John Wiley\&Sons, 2003) p. 77.

20) L. Hultman: Vacuum 57 (2000) 1-30.

21) P. K. Huang and J. W. Yeh: Surf. Coat. Technol. 203 (2009) 18911896. 